\title{
PESQUISA DA INFECÇÃO NATURAL POR YERSINIA PESTIS, EM PULICÍDEOS PROVENIENTES DE FOCOS PESTOSOS DO NORDESTE DO BRASIL.
}

\section{Darci Pascoal Brasil1, Francisco Gomes de Carvalho2 ${ }^{2}$, Célio Rodrigues de Almeida1 e Alzira Maria Paiva de Almeida1.}

\begin{abstract}
Foram avaliados três processos de acondicionamento e transporte de pulgas, objetivando análise bacteriológica para isolamento da Yersinia pestis. As três abordagens testadas foram: pulgas vivas em tubos de ensaio com tiras dobradas de papel de filtro; pulgas em soluçẫo salina; macerados de pulgas em meio de Cary-Blair. Os dois últimos métodos foram quase iguais e superiores ao primeiro. Foram analisadas pelas três técnicas, um total de 29.512 "pools" de pulicídeos provenientes de focos de peste do Nordeste do Brasil no periodo de 1966 a 1982. Deste total, $236(0,80 \%)$ dos "pools" foram positivos por cultura e/ou inoculação em animais sensiveis.
\end{abstract}

Palavras-chaves: Yersinia pestis. Pulicideos. Vigilância. Controle da peste.

A peste tem sido um sério problema para a humanidade desde a mais remota antigüidade 15 . Atualmente, apesar dos avanços científicos e tecnológicos a infecção persiste nos focos naturais de quase todos os continentes ${ }^{22}$. No Brasil há vários focos disseminados na Regiāo Nordeste sendo os mais ativos os dos Estados do Ceará, Pernambuco, Paraiba e Bahia 13458 , além de um pequeno foco na Serra dos Órgãos, no Estado do Rio de Janeiro ${ }^{6}$. Sendo uma das doenças de notificação obrigatória a nivel internacional e sujeita a quarentena 21 , os paises que têm peste em seus territórios, devem envidar todos os esforços possíveis para evitar a propagação da infecção pelos roedores e seus ectoparasitos. O Comitê de Peritos em Pestes da OMS ${ }^{23}$ recomenda a vigilância permanente nos focos e nas áreas com história de infecção no passado. Capturas sistemáticas e exames regulares dos roedores e seus ectoparasitos, permitem acompanhar a evolução das atividades da infecção.

Neste trabalho avalia-se a pesquisa de Yersinia pestis nos pulicídeos dos focos de peste do Nordeste do Brasil no período de 1966 a 1982 e os métodos empregados para o transporte de pulgas com vistas ao isolamento do bacilo, possibilitando que medidas profiláticas sejam acionadas.

\section{MATERIAL E MÉTODOS}

As pulgas foram coletadas durante os trabalhos do Plano Piloto de Peste em Exu ${ }^{10}$ e pelas equipes do

1. Laboratório de Peste. Centro de Pesquisas Aggeu Magalhães, Recife, PE.

2. Laboratório de Peste. 56230 Exu, PE.

Endereço para correspondência: Dr. Darci Pascoal Brasil. Caixa Postal 7472 - 50730 Recife, PE, Brasil.

Recebido para publicação em 26/06/89.
Laboratório de Peste do Centro de Pesquisas Aggeu Magalhães e da Campanha Contra a Peste das Diretorias Regionais da SUCAM/MS dos Estados de Pernambuco, Paraiba, Ceará, Alagoas e Bahia.

No periodo de 1966 a 1974 , os pulicídeos eram levados vivos ao laboratório em tiras dobradas de papel de filtro, no interior de pequenos frascos de vidro ou tubos de ensaio fechados com gaze. A identificação especifica dos pulicídeos, as análises bacteriológicas e/ou inoculações, em animais sensiveis, eram realizadas nas primeiras 24 horas após a coleta.

No periodo de 1975 a 1982, foram adotados os processos de conservação dos pulicideos em solucão salina a $2,5 \% 9$ ou semeio de macerados de "pools" de pulicídeos, no meio de Cary \& Blair 131420 , para transporte e análise em um laboratório central. $\mathrm{O}$ número de pulgas de cada "pool" variava de 1 a 20 , entretanto houve ocasiões em que esse limite foi ultrapassado. Os pulicídeos eram agrupados por espécie e hospedeiro ou origem. Os "pools", conservados em salina, eram lavados por 10 minutos em álcool etílico a $70 \%$ e depois em salina $(0,85 \%)$ estéril, sendo em seguida macerados estérilmente com bastão de vidro, diluidos em algumas gotas de salina e semeados e/ou inoculados em animais sensiveis à peste ${ }^{18}$ (camundongos ou Bolomys lasiurus $=Z$ ygodontomys lasiurus pixuna). As culturas eram incubadas a $37^{\circ} \mathrm{C}$ durante 48 horas e colônias com características de $Y$. pestis, eram repicadas em caldo peptonado para teste com o bacteriófago antipestoso e isolamento da cepa ${ }^{17}$.

Os animais inoculados ficavam em observação e os que morriam eram processados conforme descrito por Almeida e cols ${ }^{7}$ seguindo a metodologia de Baltazard e cols 11 e Bahmanyar \& Cavanaugh ${ }^{9}$. Os "pools" de pulgas, macerados e semeados para observação e transporte no meio de Cary \& Blair, eram também analisados por cultivo e/ou inoculações. 
Brasil DP, Carvalho FG, Almeida CR, Almeida AMP. Pesquisa da infeccào natural por Yersinia pestis, em pulicídeos provenientes de focos pestosos do Nordeste do Brasil. Revista da Sociedade Brasileira de Medicina Tropical 22: 177-181, Out-Dez, 1989.

Tabela I - Distribuiçảo por foco dos "pools" de pulićdeos analisados e infectados no periodo de 1966 a 1982

\begin{tabular}{|c|c|c|c|c|c|c|c|c|c|c|c|c|c|c|c|c|c|c|c|c|}
\hline \multirow{4}{*}{ Periodo } & \multicolumn{20}{|c|}{ Focos } \\
\hline & \multirow{2}{*}{\multicolumn{3}{|c|}{ Chapada do Araripe }} & \multirow{2}{*}{\multicolumn{3}{|c|}{ Triunfo }} & \multirow{2}{*}{\multicolumn{3}{|c|}{ Agreste/PE }} & \multicolumn{3}{|c|}{ Chapada da Borborema } & & & \multirow{2}{*}{\multicolumn{3}{|c|}{ Norte do Ceará }} & \multirow{3}{*}{\multicolumn{2}{|c|}{$\begin{array}{cc}\text { Total } \\
\text { Exam } & \text { Pos }\end{array}$}} & \multirow[b]{3}{*}{$\%$} \\
\hline & & & & & & & & & & Enc & ta Lest & & & ente Sul/AL & & & & & & \\
\hline & Exam & Pos & $\%$ & Exam & Pos & $\%$ & Exam & Pos & $\%$ & Exam & Pos & $\%$ & Exam & Pos & Exam & Pos & $\%$ & & & \\
\hline$\overline{1966}$ & 231 & 1 & 0,43 & & - & & & - & & & - & & & - & & - & & 231 & 1 & 0,43 \\
\hline 1967 & 1889 & 56 & 2,96 & & - & & & - & & & - & & & - & & - & & 1889 & 56 & 2,96 \\
\hline 1968 & 1723 & 19 & 1,10 & & - & & & - & & & - & & & - & & - & & 1723 & 19 & 1,10 \\
\hline 1969 & 1070 & 29 & 2,71 & & - & & & - & & & - & & & - & & - & & 1070 & 29 & 2,71 \\
\hline 1970 & 756 & 32 & 4,23 & & - & & & - & & & - & & & - & & - & & 756 & 32 & 4,23 \\
\hline 1971 & 1328 & 29 & 2,18 & & - & & & - & & & - & & & - & & - & & 1328 & 29 & 2,18 \\
\hline 1972 & 897 & 11 & 1,23 & & - & & & - & & & - & & & - & 114 & 1 & 0,88 & 1011 & 12 & 1,19 \\
\hline 1973 & 484 & - & & & - & & & - & & & - & & & - & & - & & 484 & - & \\
\hline 1974 & 859 & 35 & 4,07 & & - & & & - & & & - & & & - & & - & & 859 & 35 & 4,07 \\
\hline 1975 & 395 & 15 & 3.80 & 71 & - & & 1134 & - & & & - & . & . & - & & - & & 1600 & 15 & 0,93 \\
\hline 1976 & 142 & 1 & 0,70 & 106 & - & & 755 & - & & & - & & - & - & & - & & 1003 & 1 & 0,10 \\
\hline 1977 & 232 & - & & 127 & - & & 442 & - & & & - & & & - & 141 & - & & 942 & - & \\
\hline 1978 & 606 & - & & 254 & - & & 599 & - & & 13 & - & & 113 & - & 1078 & - & & 2663 & - & \\
\hline 1979 & 1287 & - & & 315 & 2 & 0,63 & 596 & 5 & 0,84 & & - & & 398 & - & 1319 & - & & 3915 & 7 & 0,18 \\
\hline 1980 & 1755 & - & . & 303 & - & & 516 & - & & 221 & - & & 443 & - & 1104 & - & & 4342 & - & \\
\hline 1981 & 534 & - & & 526 & - & & 482 & - & & 320 & - & & 295 & - & 649 & - & & 2806 & - & \\
\hline 1982 & 178 & - & & 406 & - & & 1156 & - & & 683 & - & & 244 & - & 223 & - & & & 2890 & - \\
\hline Total & 14366 & 228 & 1,59 & 2108 & 2 & 0,09 & 3680 & 5 & 0,08 & 1237 & - & & 1493 & - & 4628 & 1 & $0, \overline{02}$ & 29512 & 236 & 0,80 \\
\hline
\end{tabular}

Exam = Numero de "pools" de pulicideos examinados. Pos = Numerode "poots" de pulicideos positivos.

A fim de avaliar a eficácia dos métodos recomendados para o transporte de pulgas para isolamento da Y. pestis, 80 "pools" de Xenopsylla cheopis (5 pulgas por "pool") colonizadas e infectadas no laboratório com a cepa P.PB 862, segundo a metodologia de Baltazard e Eftekhari 11 foram acondicionados nas seguintes condições: 20 "pools" em tiras dobradas de papel de filtro, colocados em tubos de ensaio mantidos a temperatura-ambiente e 20 "pools" a $4 \circ \mathrm{C}, 20$ "pools" em solução salina a $2,5 \%$ e 20 "pools" macerados e semeados no meio de Cary \& Blair. Dois "pools" conservados em cada uma das condições citadas, foram analisados por cultura em gelose e MacConkey agar a intervalos regulares até 90 dias.

\section{RESULTADOS}

A Tabela 1 mostra a distribuição por foco dos "pools" de pulicídeos analisados e infectados no periodo de 1966 a 1982 e observa-se que a $Y$. pestis foi encontrada em $236(0,80 \%)$ dos 29.512 "pools" examinados.

A distribuição específica dos pulicideos examinados e infectados, no período de 1966 a 1982, encontra-se na Tabela 2 e verifica-se que o número de "pools" de Polygenis (Polygenis bolshi jordani e, Polygenis tripus) do Foco da Chapada do Araripe infectados pela $Y$. pestis, foi significativamente maior. Quanto às pulgas Xenopsylla, Ctenocephalides e Pulex irritans, foram encontradas infectadas apenas no foco da Chapada do Araripe, provavelmente em decorrência da metodologia empregada nas coletas e ao processamento imediato.
Os resultados dos trabalhos realizados sobre a conservação de pulicídeos para transporte e análise posterio, encontram-se na Tabela 3. A $Y$. pestis só foi recuperada nos dois primeiros dias, entre os pulicídeos conservados em papel de filtro a temperatura ambiente, e até 15 dias quando a conservação foi realizada a $4^{\circ} \mathrm{C}$. Após esses periodos, o bacilo desaparece das pulgas e não se obtém nenhum crescimento nas culturas. Em pulgas conservadas em solução salina a $2,5 \%$ ou maceradas e colocadas no meio de Cary \& Blair, a $Y$. pestis foi encontrada durante todo o período de experimentos. Nessas condições algumas amostras que resultaram negativas apresentavam crescimento abundante de outras bactérias, principalmente não fermentadoras, e bacilos esporulados gram positivos. Estas bactérias também são freqüentemente encontradas nas amostras recebidas dos campos para exames (dados não apresentados).

\section{DISCUSSÃO}

A maioria das pulgas infectadas, era originária do foco da Chapada do Araripe/PE, no período de 1966 a 1976. Avaliando os resultados da pesquisa da $Y$. pestis nos roedores dos focos do Nordeste do Brasil no período de 1966 a 1982, Almeida e cols ${ }^{2}$, também observaram que a maioria dos animais infectados era proveniente do Foco da Chapada do Araripe, no período de 1966 a 1974. Nesse foco, o bacilo da peste foi encontrado entre os pulicídeos quase ininterruptamente, no periodo de 1966 a 1976, exceto no ano de 1973 quando também não foi detectado nos roedores ou seres humanos ${ }^{1}$. Depois de 1976, não foi mais encontrado entre os pulicídeos desse foco, apesar da 
Brasil DP, Carvalho FG, Almeida CR, Almeida AMP. Pesquisa da infecção natural por Yersinia pestis, em pulicideos provenientes de focos pestosos do Nordeste do Brasil. Revista da Sociedade Brasileira de Medicina Tropical 22: 177-181, Out-Dez, 1989.

Tabela 2 -Distribuição especifica dos "pools" de pulicídeos examinados e infectados no periodo de 1966 a 1982.

\begin{tabular}{|c|c|c|c|c|c|c|c|c|c|c|c|c|c|c|}
\hline \multirow{3}{*}{ Focos } & \multicolumn{12}{|c|}{ Pulicideos } & & \\
\hline & \multicolumn{2}{|c|}{ Polyg } & \multicolumn{2}{|c|}{ Xeno } & \multicolumn{2}{|c|}{ Cteno } & \multicolumn{2}{|c|}{ Pulex } & \multicolumn{2}{|c|}{ Adorat } & \multicolumn{2}{|c|}{$\mathrm{S} /$ inform } & \multicolumn{2}{|c|}{ Total } \\
\hline & Exam & Pos & Exam & Pos & Exam & Pos & Exam & Pos & Exam & Pos & Exam & Pos & Exam & Pos \\
\hline Chapada do Araripe & 9101 & 203 & 1731 & 19 & 569 & 1 & 2788 & 5 & 30 & - & 147 & - & 14366 & 228 \\
\hline Triunfo & 1356 & 2 & 518 & - & 56 & - & 132 & - & - & - & 46 & - & 2108 & 2 \\
\hline Agreste/PE & 4129 & 5 & 458 & - & 310 & - & 729 & - & 47 & - & 7 & - & 5680 & 5 \\
\hline Encosta Leste/PB & 190 & - & 14 & - & 20 & - & 53 & - & 1 & - & 959 & - & 1237 & - \\
\hline Vertente Sul/AL & 647 & - & 654 & - & 63 & - & 128 & - & 1 & - & - & - & 1493 & - \\
\hline Norte do Ceará & 2032 & 1 & 1373 & - & 247 & - & 638 & - & 14 & - & 324 & - & 4628 & I \\
\hline Total & 17455 & 211 & 4748 & 19 & 1265 & 1 & 4468 & 5 & 93 & - & 1483 & - & 29512 & 236 \\
\hline
\end{tabular}

Polyg - Polygenis bohlsijordani $\mathrm{e}$ Polygenis tripus; $\mathrm{Xeno}=$ Xenopsylla sp; $\mathrm{Cteno}=$ Ctenocephalides sp.; $\mathrm{Pulex}=$ Pulex irritans; Adorat $=$ Adoratopsylla a. antiquorum; $\mathrm{S} /$ inform: $=$ sem informação; Exam $=$ examinados; Pos $=$ positivos.

Tabela 3 - Avaliação dos processos de conservação e transporte de pulicídeos para isolamento da Yersinia pestis.

\begin{tabular}{|c|c|c|c|c|c|c|c|c|}
\hline \multirow{3}{*}{ Dias } & \multicolumn{2}{|c|}{ Papel filtro TA } & \multicolumn{2}{|c|}{ Papel filtro $+4^{\circ} \mathrm{C}$} & \multicolumn{2}{|c|}{ Salina $2,5 \%$ TA } & \multicolumn{2}{|c|}{ Cary-Blair TA } \\
\hline & \multicolumn{2}{|c|}{ No de "pools" } & \multicolumn{2}{|c|}{ No de "pools" } & \multicolumn{2}{|c|}{ № de "pools" } & \multicolumn{2}{|c|}{ № de "pools" } \\
\hline & Exam & Pos & Exam & Pos & Exam & Pos & Exam & Pos \\
\hline 1 & 2 & 1 & 2 & 2 & 2 & 2 & 2 & 1 \\
\hline 2 & 2 & 2 & 2 & 1 & 2 & 2 & 2 & 2 \\
\hline 5 & 2 & - & 2 & 2 & 2 & 2 & 2 & 1 \\
\hline 6 & 2 & - & 2 & 2 & 2 & 2 & 2 & 1 \\
\hline 7 & 2 & - & 2 & 2 & 2 & 2 & 2 & - \\
\hline 8 & 2 & - & 2 & 2 & 2 & 2 & 2 & 2 \\
\hline 15 & 2 & - & 2 & 1 & 2 & 1 & 2 & 1 \\
\hline 30 & 2 & - & 2 & - & 2 & 2 & 2 & 1 \\
\hline 60 & 2 & - & 2 & - & 2 & 1 & 2 & 2 \\
\hline 90 & 2 & - & 2 & - & 2 & 1 & 2 & 2 \\
\hline
\end{tabular}

TA = Temperatura ambiente; Exam = Número de "pools" (5 pulgas por "pools") examinados; Pos = Número de "pools" positivos.

ocorrência de peste humana e de roedores 1 . Nos outros focos, a presença uia $Y$. pestis foi observada entre os pulicídeos apenas no ano de 197.9, no Foco de Triunfo, associada à peste humana e de roedores $18 \mathrm{e}$ no agreste pernambucano, que faz parte do Foco da Chapada da Borborema, não tendo sido encontrada nos pulicideos das outras áreas estudadas desse foco (Encosta Leste/PB e Vertente Sul/AL), embora tenha sido encontrada nos roedores originados da Encosta Leste/PB 12 . No Foco do Norte do Ceará, o bacilo da peste não foi encontrado entre os pulicídeos no período de 1976 a 1982, apesar da ocorrência de peste humana e de roedores 18 . Conforme foi observado em relação à pesquisa da $Y$. pestis entre os roedores ${ }^{2}$, as diferenças nos percentuais de positividade obtidos entre os pulicídeos dos diversos focos, podem ser atribuídas em grande parte à metodologia empregada nas coletas dos espécimes para exames de laboratório. Como no período de 1966 a 1974 as pulgas eram processadas no dia da coleta, o bacilo podia ser detectado no prazo de 24 a 96 horas pelo teste rápido com o bacteriófago antipestoso ${ }^{17}$, o que permitia acompanhar os rastilhos epizoóticos, concentrando as coletas nos locais infectados e obter maior quantidade de espécimes infectados. Após 1975, tendo sido adotado o sistema de enviar os espécimes para exames nos laboratórios centrais, as pulgas passaram a ser analisadas depois de várias semanas ou meses de coletadas. Por conseguinte, ao invés de serem orientadas pelos resultados dos exames de laboratório, as coletas foram realizadas segundo um cronograma préfixado anualmente, o que impossibilitava o acompanhamento dos rastilhos epizoóticos.

Polygenis sp. parasita principalmente os roedores silvestres mas pode também ser encontrada nos 
Brasil DP, Carvalho FG, Almeida CR, Almeida AMP. Pesquisa da infeccào natural por Yersinia pestis, em pulicideos provenientes de focos pestosos do Vordeste do Brasil. Revista da Sociedade Brasileira de Medicina Tropical 22: 177-181, Out-Dez, 1989.

roedores comensais e, embora raramente, no homem e livres no piso de suas moradias 1619 . Karimi e cols 19 demonstraram experimentalmente que a Polygenis sp. é capaz de picar o homem e possui grande capacidade vetora. A Xenopsylla é o principal parasita dos roedores comensais (Rattus rattus $s p$ ) porém também é encontrada entre os roedores silvestres, no homem, ou livres no solo de suas moradias ${ }^{17}$. Segundo Karimi e cols ${ }^{17}$, surtos humanos familiares, quando vários membros de uma família são infectados no mesmo periodo, são geralmente resultado da contaminação pelas Xenopsylla liberadas nas habitações após a morte dos ratos hospedeiros infectados, enquanto que os casos humanos isolados, podem ser atribuidos à contaminação nos campos pelas pulgas infectadas dos roedores silvestres. Karimi e cols 17 mostraram que a Pulex e Ctenocephalides são os pulicideos mais numerosos nas habitações do Foco da Chapada do Araripe assim como sobre os seres humanos e também atribuem importância à estas espécies nas contaminações intradomiciliares pela peste. A Adoratopsylla, principal ectoparasita dos carnívoros silvestres (Marsupiais), não foi encontrada infectada, apesar da infecção haver sido detectada nos animais hospedeiros 1 .

Embora reconheçam a eficácia de alguns métodos de conservação e transporte da $Y$. pestis 131424 , Almeida e cols ${ }^{2}$ salientam a importância da rapidez das análises das amostras coletadas para a pesquisa da $Y$. pestis, no rastreamento da peste. De maneira semelhante ao que foi observado entre os roedores, somente a análise dos pulicídeos logo após a coleta, como foi realizado no foco da Chapada do Araripe/PE, permite acompanhar os rastilhos epizoóticos e possibilita o acionamento das medidas de profilaxia ofensiva (despulização das habitações) em tempo oportuno.

\section{SUMMARY}

Three different containment transport processes of fleas were evaluated as an approach to the bacteriologic isolation of Yersinia pestis. The three methods employed were: live fleas in glass tubes containing pieces of wrapped filter paper; dead fleas in saline solution; and macerated fleas in Cary-Blair culture medium. The two latter methods were almost equal and superior to the first method. A total of 29512 flea pools, from plague foci in Northeast Brazil collected during 1966 to 1982 were evaluated by the three methods. Among these samples, 236 $(0.80 \%)$ flea pools were positive with regard to bacteriological cultivation and/or infection of susceptible animals.

Key-words: Yersinia pestis. Vector Control fleas. Plague surveillance.

\section{REFERÊNCIAS BIBLIOGRÁFICAS}

1. Almeida AMP, Brasil DP, Carvalho FG, Almeida CR Isolamento da Yersinia pestis nos focos pestosos do Nordeste do Brasil no periodo de 1966 a 1982. Revista do Instituto de Medicina Tropical de São Paulo 27: 207-218, 1985a.

2. Almeida AMP, Brasil DP, Carvalho FG, Almeida CR Pesquisa de Yersinia pestis em roedores e outros pequenos mamíferos nos focos pestosos do Nordeste do Brasil no periodo de 1966 a 1982. Revista de Saúde Pública, São Paulo 21:265-267, 1987.

3. Almeida AMP, Brasil DP, Leal NC, Melo MEB, Rego RVB, Almeida, CR. Estudos bacteriológicos e sorológicos de um surto de peste no Estado da Paraiba, Brasil. Memórias do Instituto Oswaldo Cruz 84:249-256, 1989.

4. Almeida AMP, Brasil DP, Melo MEB, Leal NC, Almeida CR. Deteç̧ão da peste no Estado da Bahia. Revista de Microbiologia, São Paulo 16:232-233, 1985.

5. Almeida AMP, Brasil DP, Melo MEB, Leal NC, Almeida CR. Importância dos carnivoros domésticos (çães e gatos) na epidemiologia da peste nos focos do Nordeste do Brasil. Cadernos de Saúde Pública, RJ 1:49-55, 1988

6. Almeida AMP, Brasil DP, Melo MEB, Nakasaua M, Almeida CR. Demonstração de atividade pestosa no foco da Serra dos Órgāos (Rio de Janeiro, Brasil) no período de 1983 a 1984, através de exames sorológicos em roedores. Revista de Microbiologia, São Paulo 16:280-281, 1985.

7. Almeida CR, Almeida AMP, Brasil DP, Dantas Sobrinho J, Leal MA. Estudo do roedor Akodon arviculoides, Wagner, 1842 (Cricetidae). Importância nos focos pestosos do Brasil. Memórias do Instituto Oswaldo Cruz 81:407-414, 1986.

8. Almeida CR, Almeida AMP, Vieira JB, Guida U, Butler T. Plague in Brazil during two years of bacteriological and serological surveillance. Bulletin of the World Health Organization 59:591-597, 1981

9. Bahmanyar M, Cavanaugh DC. Plague Manual. World Health Organization, Geneve, 1976.

10. Baltazard M. Viagem de Estudos ao Brasil para a organizaçāo de um projeto de pesquisa sobre a peste. Revista Brasileira de Malariologia e Doenças Tropicais 20:335-366, 1968.

11. Baltazard M, Davis DHS, Devignat R, Girard D, Gohar MA, Kartman L, Meyer KF, Parker MT, Pollitzer R, Prince FM, Quan SF, Wagle P. Recommended laboratory methods for the diagnosis of plague. Bulletin of the World Health Organization 14:457-509, 1956.

12. Baltazard M, Eftekhari M. Technique de récolte, de manipulation et d'élevage des puces de rongeurs. Bulletin de la Organization Mondiale de la Santé 16:436-440, 1957.

13. Cary SG, Blair EB. New transport medium for shipment of clinical specimens. I. Fecal specimens. Journal of Bacteriology 88:96-98, 1964.

14. Cavanaugh DC, Vivona S, Do-Van-Quy, Gibson, FL, Deuber GL, Rust Jr JH. A transport medium for specimens containing $P$. pestis. Bulletin of the World Health Organization 37:455-459, 1967.

15. Coura JR, Almeida CR, Almeida AMP. Peste in: Amato 
Brasil DP, Carvalho FG, Almeida CR, Almeida AMP. Pesquisa da infeccão natural por Yersinia pestis, em pulicideos provenientes de focos pestosos do Nordeste do Brasil. Revista da Sociedade Brasileira de Medicina Tropical 22: 177-181, Out-Dez, 1989.

Neto V, Baldy JLS (eds). Doenças Transmissíveis. Savier. São Paulo 3a ed. p. 691-698, 1989.

16. Guimaràes LR Contribuição à epidemiologia da peste endêmica no Nordeste do Brasil e Estado da Bahia. Estudo das pulgas encontradas nessa região. Revista Brasileira de Malariologia e Doenças Tropicais 24:95$163,1972$.

17. Karimi Y. Diagnostique rapide de l'infection pesteuse au laboratoire. Bulletin de la Societé de Pathologie Éxotique 1:45-48, 1978.

18. Karimi Y, Almeida CR, Almeida AMP. La peste experimentale chez les rongeurs du Brésil. Déductions Épidémiologiques. Bulletin de la Societé de Pathologie Éxotique 67:591-601 1974

19. Karimi Y, Eftekhari M, Almeida CR. Sur l'écologie des puces impliquées dans l'epidémiologie de la peste et le rôle éventuel de certains insectes hématophages dans son processus au Nord-Est du Bresil. Bulletin de-la Societé de Pathologie Éxotique 67:583-591, 1974.
20. Mello MT, Paracampo H, Santos DA. Emprego do meio de Cary Blair para conservação e transporte de material suspeito de peste em zonas rurais. Revista Brasileira de Malariologia e Doenças Tropicais 21:767-773, 1969.

21. Organización Mundial de la Salud. Eglamento Sanitario Internacional. Ginebra, 1974.

22. Poland JD, Bames A. Plague. In: Steele JH (ed) CRC Handbook Series in Zoonoses. Section A: Bacterial, Rickettisial and Mycotic Diseases. Boca Raton, CRC Press p. 515-558, 1979.

23. World Health Organization. Technical Report Series. WHO Expert Committee on Plague. Fourth Report 447:23-25, 1970.

24. Zebral AA, Costa GA. Eficácia de alguns meios de cultura na conservação de amostras de Yersinia pestis. Revista Brasileira de Malariologia e Doenças Tropicais 31:5-17, 1969. 